\section{Kidney \\ Blood Pressure Research}

Review

\title{
Exosomes: The New Mediator of Peritoneal Membrane Function
}

\author{
Manshu Yu Jun Shi Meixiao Sheng \\ Affiliated Hospital of Nanjing University of Chinese Medicine, Nanjing, China
}

\section{Key Words}

Exosomes • Peritoneal membrane function • Fibrosis • Angiogenesis

\begin{abstract}
Fibrosis and angiogenesis are the most common processes that result in progressive peritoneal tissue remodeling and, eventually, peritoneal membrane dysfunction. The role of exosomes, which contributes to intercellular communication, in these processes has been neglected. Various biomolecules, including DNA, mRNA, proteins, lipids, and particular certain miRNAs, can be transferred by exosomes to local, neighboring and distal cells. Upon stimulation by cytokines or other microenvironment stimuli, donor cells release a mass of exosomes to peritoneal mesothelial cells, further affecting fibrosis and angiogenesis. This important exosomes-mediated intracellular communication is thought to regulate peritoneal membrane function. Understanding the molecular mechanisms of these processes, targeting changes in exosomes and regulating exosomal miRNAs will advance therapeutic methods for protecting peritoneal membrane function.

\section{Introduction}

The structure of the peritoneal membrane (PM) is composed of a single layer of highly specialized mesothelial cells that lines a compact zone, which includes few fibroblasts, mast cells, macrophages and blood vessels [1]. This zone also covers an underlying stroma containing extracellular matrix (ECM) and stromal cells [2]. Peritoneal mesothelial cells (PMCs), as active participants, play a significant role in maintaining normal PM function.

Several factors contribute to PM dysfunction, including continuous peritoneal dialysis (PD), tumor with peritoneal metastasis, traumatic surgery, and toxic reagents. The most frequent findings for histomorphological peritoneal problems are submesothelial fibrosis, angiogenesis and hyalinizing vasculopathy [3]. PMCs have been proposed to be the cells primarily responsible for the pathogenesis of PM dysfunction. In PD, after longterm exposure to various glucose degradation products (GDPs) and advance glycation end 


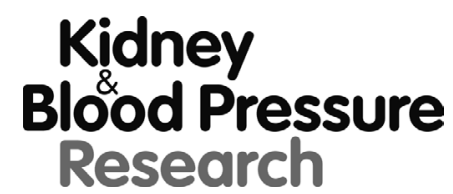

\begin{tabular}{l|l}
\hline Kidney Blood Press Res 2018;43:1010-1022 \\
\hline \begin{tabular}{l|l} 
DOI: 10.1159/000490821 & (c) 2018 The Author(s). Published by S. Karger AG, Basel \\
Published online: 25 June, 2018 & www.karger.com/kbr
\end{tabular} \\
\hline
\end{tabular}

Yu et al.: Exosomes Mediate Peritoneal Membrane Function

productions, PMCs undergo a de-differentiation process, and peritoneal fibrosis (PF) ensues [4]. Continual hyperosmotic, hyperglycemic and acidic dialysis solutions, as well as dwelling practice-related mechanical stress, may cause acute and chronic injuries of the PM. In these conditions, the prevalence and severity of fibrosis and angiogenesis accelerate over time during PD [5]. In addition, peritoneal metastasis negatively affects PM function. Factors that regulate tumor seeding, angiogenesis and the formation of pre-metastatic niche and those that mediate damage responses are released into the ascites [6]. PMCs subsequently aggravate this invasion by proliferating, migrating or altering their phenotype. Thus, in biologically incompatible environments or during peritoneal metastasis or progressive peritoneal tissue remodeling, fibrosis and angiogenesis occur and gradually deteriorate the tissue, ultimately resulting in PM dysfunction.

Exosomes are 40- to 100-nm-diameter vesicles consisting of a lipid bilayer generated from secretory multivesicular bodies that in turn fuse with the plasma membrane prior to release into the extracellular environment [7]. Exosomes are secreted by platelets [8], cytotoxic T lymphocytes [9], dendritic [10], epithelial [11-12], muscle [13], tumor [14], mast [15], mesenchymal stem cells (MSCs) [16], adipocytes [17] and others. They stably exist in various body fluids and can be extracted from ascites, nasal lavage fluid, saliva, serum, plasma, breast milk, urine, as well as cell culture medium [18]. Stress or disease conditions can stimulate exosomes biogenesis and release [19]. Exosomes play a crucial role in cellto-cell communication by transporting DNA, messenger RNA (mRNA), microRNA (miRNA), proteins and lipids, which take part in almost all physiological and pathological processes [20]. Among the multiple components of exosomes, miRNAs have been proposed to be critical factors, as they largely determine the functional consequences of exosomes signaling on recipient cells [21].

Interestingly, recent studies suggested that exosomes can cause several pathological processes that mediate PM function in fibrosis and angiogenesis [22]. Manipulating exosomes, PMCs, fibrosis and angiogenesis may represent a novel therapeutic strategy for protecting PM function. In this review, we highlight the role of exosomes in mediating PM function within the context of fibrosis and angiogenesis.

\section{Molecular network of fibrosis and angiogenesis in modulating PM function}

$\mathrm{PF}$ has a crucial influence on PM structure and function. The pathogenesis of PF is characterized by a decreasing number of mesothelial cells and progressive submesothelial thickening with an increasing myofibroblast presence [23]. The accumulation of collagenproducing fibroblasts and excessive deposition of ECM disrupt normal peritoneal architecture and homeostasis [24]. During initial phases, epithelial-mesenchymal transition (EMT) plays a central role in the alterations of PMCs, leading to fibrosis. EMT is the stepwise loss of epithelial characteristics and the acquisition of a myofibroblast-like phenotype [25]. This complex pathological process consists of disruption of intercellular junctions, loss of apicalbasolateral polarity, cytoskeletal remodeling and acquisition of migratory and invasive characteristics [26]. Mesothelial-derived myofibroblasts induce the accumulation of ECM proteins and contraction of the repairing tissue, thus prompting fibrosis [27, 28].

In $\mathrm{PD}$, the use of traditional bio-incompatible PD solutions with high glucose concentrations and GDPs are implicated in PF [29]. Transforming growth factor $\beta 1$ (TGF- $\beta 1$ ) plays a central role in PF through the induction of numerous pro-fibrotic events, including EMT, fibroblast proliferation and ECM deposition [30]. In fact, high glucose PD solutions stimulate TGF- $\beta 1$ synthesis and TGF- $\beta 1$-induced PF [31]. Additionally, surgical or accidental injury, as well as viral and bacterial infections, may stimulate and damage PMCs [32]. In these cases, persistent triggers cause fibrosis or scarring, impairing normal PM function [33]. In addition, peritoneal metastasis, which is significantly related to EMT, is another way to promote fibrosis [34]. Metastatic tumors infiltrate structures, contacting the visceral layer 


\section{Kidney Blood Pressure Research}

of the PM and diffusing into the peritoneal cavity. These cells attach to the mesothelium and generate metastatic PM lesions, accompanied by EMT and fibrosis [35]. In tumor metastasis, cancer cells activate essential genes and signaling pathways related to EMT, including Snail, Twist, zinc finger E-box-binding homeobox 1 (Zeb1), and insulin-like growth factor receptor (IGFR). Recent studies have indicated that IGFR may induce EMT through Snail in mammary epithelial cells and through the up-regulation of Zeb1 and latent TGF- $\beta 1$ [36]. Recently, epigenetic changes have been implicated in tumor metastasis and EMT. For example, silencing of the TET-mediated demethylation of anti-metastatic miR-200 promotes tumor metastasis [37].

At later stages, fibrosis occurs significantly more often in the presence of vasculopathy, such as an increased density of peritoneal blood vessels, and with submesothelial and perivascular fibrosis [38]. In PD, the release of angiogenic factors, such as basic fibroblast growth factor (bFGF), vascular endothelial growth factor (VEGF), platelet-derived growth factor (PDGF), TGF- $\beta 1$ and epidermal growth factor (EGF), leads to degradation of the vascular basement membrane and activation of endothelial cells [39]. These events are involved in the proliferation and migration of PMCs. As the lesion burden grows, PMCs are recruited to form new blood vessels and promote matrix-remodeling enzymes, improving angiogenesis. PMCs that have undergone EMT increase the potential for invasion and migration into the submesothelial zone, leading to further neovascularization [40]. Inhibiting angiogenesis ameliorates PF [41]. Similarly, metastatic tumor cells express matrix proteinases that disrupt the peritoneal blood barrier and attachment to the PM, enabling invasion into the subperitoneal space and proliferation in response to angiogenesis. Subsequently, angiogenesis is crucial for progressive PM lesions [42].

In summary, fibrosis and angiogenesis affect PM lesions during different stages, synergistically mediating PM function.

\section{The potential relevance between exosomes and PMCs}

Exosomes have buoyant density and are formed from the luminal membrane of endosomal multivesicular bodies. Endosomal multivesicular bodies are always targeted for the plasma membrane and release exosomes into the extracellular environment $[43,44]$. Exosomes harbor organelle-like lipid-bound membranous structures derived from most cell types. They provide an important molecular mechanism through which cells can affect local, neighboring, and distant cells and their environments [45]. Previous studies illuminated the exosomes-mediated regulation of various biologic functions, including intercellular communication and antigen presentation [46]. Functional exosomes always transfer genetic material from a donor cell to a recipient cell through the incorporation of DNA, mRNA, miRNA, proteins and lipids [47]. For example, during tumor progression, mRNA delivered by exosomes can affect the translational profile of recipient cells [48]. Thakur and colleagues indicated that mutated KRAS and p53 in dsDNA within pancreatic cancer cell-derived exosomes are the most frequent mutations in human pancreatic cancer. They suggested that exosomal DNA harbors these mutations and can serve as a biomarker in cancer diagnostics [49]. In another study, TGF- $\beta 1$ mRNA delivered via exosomes from fibroblasts to epithelial cells initiated an autocrine process, inducing the loss of epithelial function and leading to EMT [50].

Accumulating evidences showed that epithelial cells, mast cells, fibroblasts and adipocytes can produce increased numbers of exosomes [12, 15, 17, 51, 52]. In fact, the PM consists of three layers, including the mesothelial monolayer and loose adipose tissue. Anatomically, PMCs are crucial components with characteristics similar to those of epithelial cells. The omental or mesenteric peritoneum is composed of an abundant nest of mature adipocytes [53]. All these components are essential for normal PM function. Meanwhile, rich exosomes can be detected in PMCs (recipient cells) due to intercellular deliveries 


\section{Kidney Blood Pressure Research}

Kidney Blood Press Res 2018;43:1010-1022

\begin{tabular}{l|l}
\hline DOI: 10.1159/000490821 & (C) 2018 The Author(s). Published by S. Karger AG, Base
\end{tabular}

Published online: 25 June, 2018

www.karger.com/kb

Yu et al.: Exosomes Mediate Peritoneal Membrane Function

from other types of cell (donor cells). When donor cells are stimulated by cytokines, high glucose, hypoxia and other stimuli, they can produce numerous exosomes and subsequently transfer these exosomes to PMCs [54]. This cell-to-cell communication alters the function and phenotype of PMCs [55]. Therefore, it is plausible to suggest that a potential relationship between exosomes and PMCs is important.

In addition, several studies have indicated that exosomes derived from cancer cells cause the proliferation and transformation of PMCs [56]. In the process of peritoneal metastasis, normal PMCs become carcinoma-associated fibroblasts. The cancer cells float in the peritoneal cavity and attach to a single layer, invading through the mechanical barrier of PMCs. The underlying ECM turns into the peritoneum, omentum or bowel serosa. Furthermore, the presence of ascites, an accumulation of protein-rich exudate in the peritoneal cavity, accelerates the invasion and migration of PMCs [57]. Importantly, exosomes can be detected in PMCs after incubation with tumor-derived exosomes [54].

\section{Functional contribution of exosomes in fibrosis and angiogenesis}

Exosomes mediate fibrosis and angiogenesis through the regulation of intercellular communication. The activation of fibroblasts is recognized as a critical step in the process of fibrosis [58]. Exosomes, as peritoneal metastatic transplants from donor cells, promote TGF- $\beta 1$-induced fibrosis by transferring TGF- $\beta 1$. As the recipient cells, PMCs show increased ability to proliferate, migrate and recruit numerous fibroblasts [59]. Additionally, data from some clinical samples indicated that TGF- $\beta 1$ may be overexpressed in malignant ascitesderived exosomes, and this high concentration of TGF- $\beta 1$ is responsible for fibrosis [54]. TGF- $\beta 1$ mRNA is delivered by exosomes to fibroblasts and in turn translated into protein that initiates an autocrine process, ultimately leading to proliferation, EMT and type I collagen (COL-1) production in neighboring fibroblasts [50]. Furthermore, exosomes enhance the expression of EMT markers and adhesion molecules via TGF- $\beta 1$, including $\alpha$-smooth muscle actin ( $\alpha$-SMA), E-cadherin, fibronectin (FN), laminin gamma-1 (LAMC-1), hyaluronan (HA), and vascular cell adhesion molecule-1 (VCAM-1) [60]. Similarly, after exosomes treatment, the expression of $\alpha$-SMA, FN, LAMC- 1 and HA increased, while the expression of E-cadherin and VCAM- 1 decreased. Indeed, TGF- $\beta 1$ expressed at the exosomes surface can increase factors related to fibroblast-myofibroblast differentiation [61]. Thus, internalized exosomes within PMCs have TGF- $\beta 1$ as their cargo, facilitating fibroblast activation, promoting the expression of adhesion molecules and the EMT of PMCs, and leading to fibrosis [62]. Briefly, TGF- $\beta 1$ mRNA transferred by exosomes is functionally important for intercellular communication. Reducing the release of exosomes and the TGF- $\beta 1$ mRNA they carry is necessary to inhibit the progression of fibrosis [63].

In addition, the administration of exosomes significantly mediates angiogenesis [64]. Angiogenesis is triggered by several growth factors and cytokines in the microenvironment [65]. The effect of exosomes on inducing angiogenesis in microenvironment has been demonstrated [66]. Enhanced microvessel density and blood perfusion in ischemic tissues have been confirmed after exosomes treatment [67]. For example, Gonzalez et al. showed that exosomes stably overexpressing hypoxia inducible factor-1 $\alpha$ (HIF-1 $\alpha$ ) exhibit increased angiogenic capacity, in part through an increase in the packaging of Jagged1 [68]. This HIF-1 $\alpha$ based mechanism regulates MSCs-derived exosomes and exosomes-mediated angiogenesis [67]. Both hypoxia and overexpression of HIF-1 $\alpha$ can increase exosomes secretion. Also, Kucharzewska et al. presented that exosomes are a potent regulator of hypoxia-dependent intercellular communication between malignant and vascular cells, suggesting a basis for the effect of exosomes during the hypoxia-driven pro-angiogenic response [69]. Moreover, exosomes promote endothelial cells proliferation, migration and tube-like formation. It has been illustrated that exosomes markedly increase endothelial proliferation by incorporating a significant amount of heat shock protein 20 (Hsp20), which activates the VEGF2 signaling 


\section{Kidney Blood Pressure Research}

pathway in endothelial cells and promotes angiogenesis [70]. Another way of exosomes has been proposed to affect angiogenesis through the mesenchymal-endothelial transition (MEndT). High mobility group box 1 protein B1 (HMGB1) plays a crucial role in angiogenesis, and inhibition of HMGB1 can alleviate vascular dysfunction and remodeling. Indeed, endothelial cell-derived exosomes promote the proliferation and angiogenesis of fibroblasts by inhibiting MEndT and decreasing HMGB1 [71].

\section{Exosomes affect fibrosis and angiogenesis via exosomal miRNAs}

\section{Exosomal miRNAs in fibrosis}

miRNAs are a major class of small non-coding RNAs that mediate post-transcriptional gene silencing through mRNA destabilization, translational inhibition and mRNA degradation [72]. miRNAs are indispensable for fibrosis, and a large number of miRNA families have been shown to modulate fibrosis [73]. Indeed, miRNAs are incorporated into exosomes, wherein they are more stable than in the cellular compartment. Released miRNAs and their binding exosomes can resist degradation from cells or in circulation in body fluids [74]. This apparent stability underscores the attractiveness of exosomal miRNAs as disease biomarkers. Also, accumulating evidences indicated that miRNAs may serve as a tool for fibrosis disease diagnosis. Abnormal urinary or plasma miRNAs expression in exosomes could be used for patient prognosis $[75,76]$. Although multiple mechanisms could play a role in generating a cellular miRNA profile, exosomes-mediated cell-cell exchange of RNA has been described as a determinant of such profiles [45]. miRNAs are packed into exosomes, which can be exchanged between cells without loss of function of the included miRNAs [77]. Most miRNAs confirmed to be related to fibrosis induce or inhibit fibrosis by targeting TGF- $\beta 1$ pathways or ECM structural proteins. Affecting EMT, inducing myofibroblast proliferation and exerting anti-apoptosis activity in myofibroblasts are other fibrosis regulatory mechanisms.

The miR-181 family of miRNAs has been associated with autophagy that subsequently lowers the level of ECM components [78]. A recent study found that exosomes treatment could attenuate the fibrotic components COL-1, Vimentin, $\alpha$-SMA, and FN. Exosomal miR-181-5p can be delivered to recipient cells in a fibrosis model and alleviate the level of fibrosis in the tissue. Specifically, miR-181-5p attenuates signal transducer and activator of transcription (STAT3) and B-cell lymphoma-2 (Bcl-2) expression. TGF- $\beta 1$ induces fibrogenic cytokines through activating STAT3, which further regulates the transcription of Bcl-2. TGF- $\beta 1$ can also increase Bcl-2 via MAPK/ERK signaling [79]. Thus, increasing the transfer of exosomal miR181-5p inhibits fibrosis by negatively regulating STAT3 and Bcl-2 gene expression.

The let-7 family of miRNAs is reported to be regulated post-transcriptionally [80]. Reduced expression of let-7 miRNAs has been implicated in EMT and enhanced cell migration. In particular, let-7 enhances fibrosis by affecting the TGF- $\beta 1$ pathway [81]. The target genes of this family include TGFBR1, Smad2, COL-1A1 and COL-1A2. The release of exosomal let-7 into the extracellular environment has been suggested to attenuate fibrosis [75, 82, 83].

miR-21, miR-378e and miR-143 were shown by Donnarumma and colleagues to exhibit a distinctly increased capacity for EMT. Decreasing exosomal delivery of miR-21, miR-378e and miR-143 can alleviate EMT [84]. Aside from the exosomal miRNAs mentioned above, other miRNAs derived from various cell types affect fibrosis (Table 1).

Table 1. Anti-fibrotic and pro-fibrogenic exosomal miRNAs

\begin{tabular}{|c|c|c|c|}
\hline miRNA & Exosomal source & Mechanism & Reference \\
\hline $\begin{array}{l}\text { miR-26a, } \\
\text { miR-200, } \\
\text { miR-205 }\end{array}$ & $\begin{array}{c}\text { podocytes, } \\
\text { mesangial cells, } \\
\text { epithelial cels }\end{array}$ & Anti-fibrosis by regulating EMT & {$[85,86]$} \\
\hline miR-29c & epithelial cells & Anti-fibrosis by inhibiting TGF- $\beta 1 /$ Smad3 pathway & {$[87,88]$} \\
\hline miR-214 & stellate cells & Anti-fibrosis by suppressing CTGF production & [89] \\
\hline miR-21 & mesothelial cells & $\begin{array}{l}\text { Pro-fibrosis by repressing PDCD } 4 \text { and stimulating } \beta \text { - } \\
\text { catenin/TCF dependent transcription }\end{array}$ & {$[90,91]$} \\
\hline miR-122 & stellate cells & $\begin{array}{l}\text { Pro-fibrosis by increasing modulators of tissue remodeling } \\
\text { (HIF- } 1 \alpha \text {, Vimentin and MAP3K) }\end{array}$ & [92] \\
\hline $\operatorname{miR}-125 b$ & $\begin{array}{l}\text { mesenchymal } \\
\text { stem cells }\end{array}$ & Pro-fibrosis by activating hedgehog signaling & [93] \\
\hline miR-210 & tumor cells & $\begin{array}{l}\text { Pro-fibrosis by converting senescence-associated features } \\
\text { to fibrosis-related myofibroblasts }\end{array}$ & {$[94,95]$} \\
\hline miR-292 & $\begin{array}{l}\text { endothelial cells, } \\
\text { progenitor cells }\end{array}$ & Pro-fibrosis by response to hypoxic conditions & [96] \\
\hline
\end{tabular}




\section{Kidney Blood Pressure Research}

Kidney Blood Press Res 2018;43:1010-1022

\begin{tabular}{l|l}
\hline DOI: $10.1159 / 000490821$ & (C) 2018 The Author(s). Published by S. Karger AG, Basel
\end{tabular}

Published online: 25 June, 2018

www.karger.com $/ \mathrm{kb}$

Yu et al.: Exosomes Mediate Peritoneal Membrane Function

\section{Exosomal miRNAs in angiogenesis}

During exosomal transfer, miRNAs may be instrumental in mediating the effects of exosomes on angiogenesis.

HIF- $1 \alpha$ is a key regulator in the cellular adaptation to hypoxia and activates various angiogenic factors [97]. Overexpression of HIF-1 $\alpha$ in MSCs (HIF-MSCs) can increase the secretion of exosomes and induce angiogenesis. However, miRNAs loaded in HIF-MSCderived exosomes, including miR-15, miR-16, miR-17, miR-31, miR-126, miR-145, miR-221, miR-222, miR-320a and miR-424, have been reported to mediate angiogenesis $[98,99]$. The mechanism of these miRNAs on angiogenesis may involve vesicular trafficking and positive regulation of cell communication, thus targeting pathways related to hypoxia or HIF-1 $\alpha$ stabilization, such as the Wnt, TGF- $\beta$ and VEGF pathways [100]. In addition, factor inhibiting hypoxia-inducible factor-1 (FIH-1), an asparaginyl hydroxylase enzyme that binds to HIF$1 \alpha$, could inhibit the angiogenesis-related transactivation function of HIF- $1 \alpha$. Exosomal miR-135b contributes to angiogenesis by accelerating HIF- $1 \alpha$ transcriptional activity via inhibition of FIH-1 [101, 102].

Intercellular tight junctions of the endothelium are important for the formation of blood vessel barriers [103]. Z0-1, in a regulatory role, affects angiogenesis and endothelial barrier formation [104]. Beyond the regulation of angiogenesis with exosomal miR-23a targeting HIF- $1 \alpha$, it is suggested that miR-23a disrupts the endothelial barrier by targeting ZO-1. Hsu and colleagues elucidated a new mechanism in which exosomal miR-23a increases angiogenesis by the HIF-1 $\alpha /$ ZO-1 pathway [105].

VEGF is another predominant inducer of normal and pathophysiological angiogenesis. Exosomes transferring miRNAs (i.e. miR-16, miR-100, miR-126) may suppress angiogenesis through regulating VEGF signaling, as an increase in exosomes elicits a marked decrease in VEGF and VEGFR-1 transcript levels [106, 107, 108]. Meanwhile, exosomal miRNAs regulate VEGF-related signaling (i.e. mTOR/HIF-1 $\alpha /$ VEGF axin). miRNAs shuttled by exosomes take part in the proliferation and angiogenesis of endothelial cells through the mTOR pathway [109].

In angiogenesis, miR-320 is delivered by exosomes into endothelial cells and mediates anti-angiogenesis functions [19]. The function of exosomal miR-320 in endothelial cells appears to be reducing Hsp20 and IGF-1. IGF-1 positively affects angiogenesis by improving the migration of vascular smooth muscle cells and exerting anti-apoptosis effects [110]. Hsp20 promotes angiogenesis by activating the VEGFR2 pathway [70].

Exosomal miR-214 is transferred into endothelial cells to aid in vascular repair, neovascularization and regeneration [111]. It has been proven to stimulate angiogenesis through repressing ataxia telangiectasia mutated (ATM) in neighboring recipient cells and affecting the proliferation and differentiation of myoblasts and T cells. ATM increases cellular senescence and targets the HIF- $1 \alpha$ pathway to further induce angiogenesis [112].

\section{Conclusion}

Patients in long-term PD or with peritoneal metastasis undergo progressive fibrosis and angiogenesis. The pathological processes of fibrosis and angiogenesis contribute to PM dysfunction. During these processes, exosomes participate in regulating PM function by affecting fibrosis and angiogenesis. Genetic information for fibrotic and angiogenic factors could be transferred by exosomes to recipient cells, further affecting target genes or signaling pathways correlated with fibrosis and angiogenesis (Fig. 1). This review summarizes recent research progress on exosomes and exosomal miRNAs in fibrosis and angiogenesis, highlighting the role of exosomes in mediating PM function. Exosomes derived from donor cells can deliver TGF- $\beta 1$ to PMCs and target EMT markers, adhesion molecules and ECM proteins, ultimately affecting fibrosis. Exosomal miR-181, Let-7, miR-26a, miR-200, miR- 


\section{Kidney Blood Pressure Research}

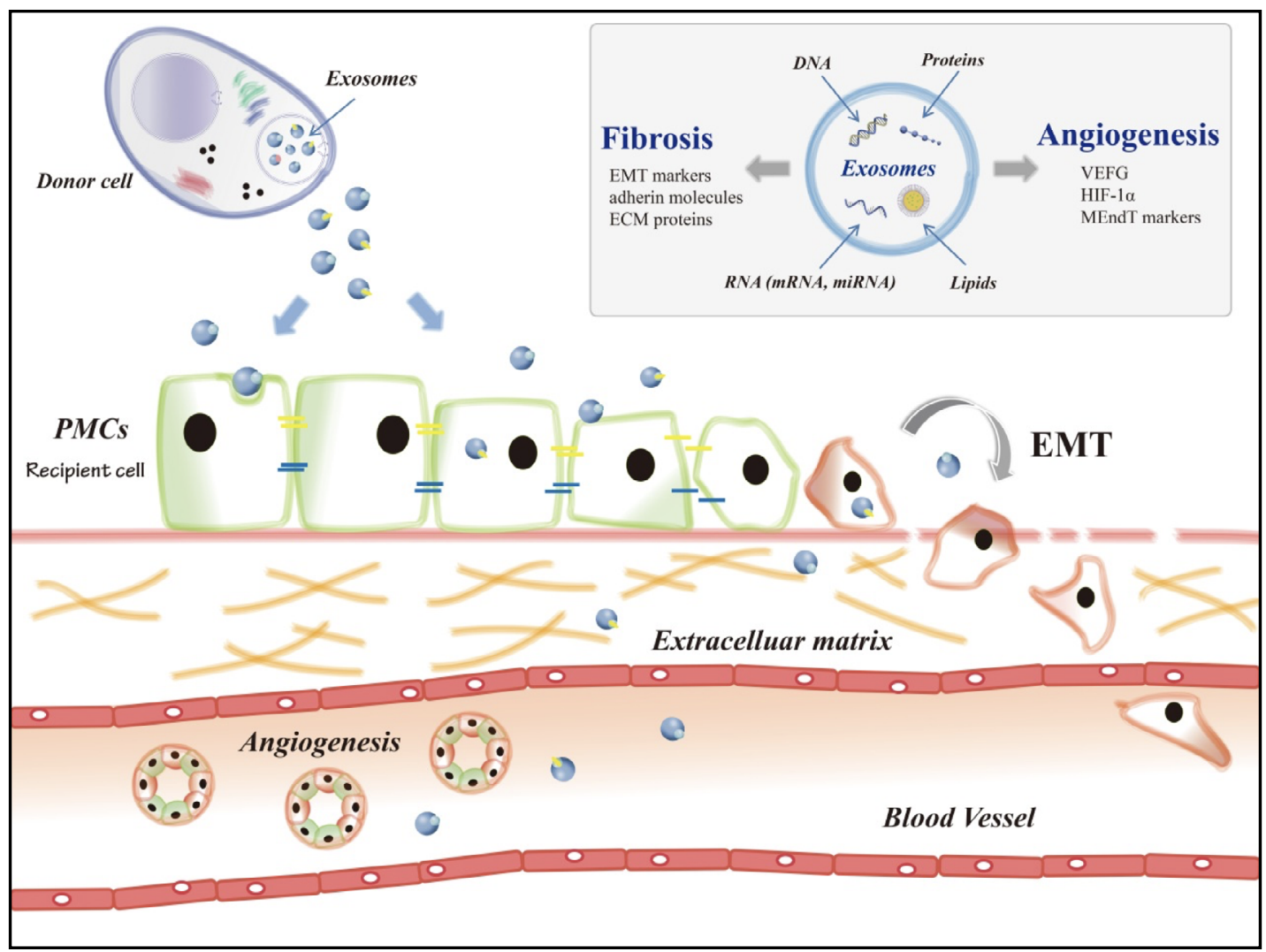

Fig. 1. Exosomes derived from donor cells affect PMCs. Exosomes affect intracellular communication by transferring DNA, RNA, protein and lipid. Donor cells can release numerous exosomes to PMCs, further affecting fibrosis and angiogenesis. Exosomes affect fibrosis by targeting EMT markers, adhesion molecules and ECM proteins. The targets of exosomes that regulate angiogenesis are VEGF, HIF-1 $\alpha$ and MEndT.

205 , miR-29c, and others mediate fibrosis by regulating the TGF- $\beta$ pathway or other fibrotic signaling pathways. Additionally, endothelial cell-derived exosomes affect angiogenesis by regulating VEGF, HIF-1 $\alpha$ and MEndT. Exosomal miR-23a, miR-16, miR-100, miR-126, miR320 and miR-214 are the primary factors involved in angiogenesis. Targeting changes in exosomes and their cargo is a therapeutic approach to modulating PM dysfunction-related fibrosis and angiogenesis.

\section{Acknowledgements}

This work was supported by grants from the National Natural Science Foundation of China (No.81473606, 81774253), Jiangsu Province Natural Science Foundation (BK20171514), Six Talent Peaks Project in Jiangsu Province (WS-033).

\section{Disclosure Statement}

The authors declare they have no conflicts of interest regarding this article. 


\section{Kidney \\ Blood Pressure Research}

\section{References}

1 Ruizcarpio V, Sandoval P, Aguilera A, Albarvizcaíno P, Perezlozano ML, Gonzálezmateo GT, Acunaruiz A, Garciacantalejo J, Botias P, Bajo MA: Genomic reprograming analysis of the mesothelial to mesenchymal transition identifies biomarkers in peritoneal dialysis patients. Sci Rep 2017;7:44941.

2 Mutsaers SE: The mesothelial cell. Int J Biochem Cell Biol 2004;36:9-16.

- 3 Del PG, Jimenez-Heffernan JA, Selgas R, Remon C, Ossorio M, Fernandez-Perpen A, Sanchez-Tomero JA, Cirugeda A, De SE, Sandoval P: Biocompatible dialysis solutions preserve peritoneal mesothelial cell and vessel wall integrity. A case-control study on human biopsies. Perit Dial Int 2016;36:129-134.

4 Yang CY, Chau YP, Chen A, Lee KS, Tarng DC, Yang AH: Targeting cannabinoid signaling for peritoneal dialysis-induced oxidative stress and fibrosis. World J Nephrol 2017;6:111-118.

5 Williams JD, Craig KJ, Topley N, Ruhland CV, Fallon M, Newman GR, Mackenzie RK, Williams GT: Morphologic changes in the peritoneal membrane of patients with renal disease. J Am Soc Nephrol 2002;13:470-479.

6 Costasilva B, Aiello NM, Ocean AJ, Singh S, Zhang H, Thakur BK, Becker A, Hoshino A, Mark MT, Molina H: Pancreatic cancer exosomes initiate pre-metastatic niche formation in the liver. Nat Cell Biol 2015;17:816826.

7 Rahman MA, Barger JF, Lovat F, Gao M, Otterson GA, Nana-Sinkam P: Lung cancer exosomes as drivers of epithelial mesenchymal transition. Oncotarget 2016;7:54852-54866.

8 Arroyo JD, Chevillet JR, Kroh EM, Ruf IK, Pritchard CC, Gibson DF, Mitchell PS, Bennett CF, Pogosovaagadjanyan EL, Stirewalt DL: Argonaute2 complexes carry a population of circulating microRNAs independent of vesicles in human plasma. Proc Natl Acad Sci U S A 2011;108:5003-5008.

-9 Mittelbrunn M, Gutierrezvazquez C, Villarroyabeltri C, Gonzalez S, Sanchezcabo F, Gonzalez MA, Bernad A, Sanchezmadrid F: Unidirectional transfer of microRNA-loaded exosomes from T cells to antigen-presenting cells. Nat Commun 2011;2:282.

10 Zitvogel L, Regnault A, Lozier A, Wolfers J, Flament C, Tenza D, Ricciardicastagnoli P, Raposo G, Amigorena S: Eradication of established murine tumors using a novel cell-free vaccine: dendritic cell-derived exosomes. Nat Med 1998;4:594-600.

11 Kulshreshtha A, Ahmad T, Agrawal A, Ghosh B: Proinflammatory role of epithelial cell-derived exosomes in allergic airway inflammation. J Allergy Clin Immunol 2013;131:1194-1203.

12 Riches A, Campbell E, Borger E, Powis S: Regulation of exosome release from mammary epithelial and breast cancer cells-a new regulatory pathway. Eur J Cancer 2014;50:1025-1034

13 Kapustin AN, Schoppet M, Schurgers LJ, Reynolds JL, Mcnair R, Heiss A, Jahnen-Dechent W, Hackeng TM, Schlieper G, Harrison P: Prothrombin loading of vascular smooth muscle cell-derived exosomes regulates coagulation and calcification. Arterioscler Thromb Vasc Biol 2017;37:e22-32.

14 Wolfers J, Lozier A, Raposo G, Regnault A, Thery C, Masurier C, Flament C, Pouzieux S, Faure F, Tursz T: Tumor-derived exosomes are a source of shared tumor rejection antigens for CTL cross-priming. Nat Med 2001;7:297-303.

15 Skokos D, Botros HG, Demeure C, Morin J, Peronet R, Birkenmeier G, Boudaly S, Mecheri S: Mast cellderived exosomes induce phenotypic and functional maturation of dendritic cells and elicit specific immune responses in vivo. J Immunol 2003;170:3037-3045.

16 Arslan F, Lai RC, Smeets MB, Akeroyd L, Choo A, Aguor ENE, Timmers L, Rijen HVV, Doevendans PA, Pasterkamp G: Mesenchymal stem cell-derived exosomes increase ATP levels, decrease oxidative stress and activate PI3K/Akt pathway to enhance myocardial viability and prevent adverse remodeling after myocardial ischemia/reperfusion injury. Stem Cell Res 2013;10:301-312.

17 Sano S, Izumi Y, Yamaguchi T, Yamazaki T, Tanaka M, Shiota M, Osada-Oka M, Nakamura Y, Wei M, Wanibuchi H: Lipid synthesis is promoted by hypoxic adipocyte-derived exosomes in 3T3-L1 cells. Biochem Biophys Res Commun 2014;445:327-333.

18 Suchorska WM, Lach MS: The role of exosomes in tumor progression and metastasis. Oncol Rep 2016;35:1237-1244.

19 Wang X, Huang W, Liu G, Cai W, Millard RW, Wang Y, Chang J, Peng T, Fan GC: Cardiomyocytes mediate antiangiogenesis in type 2 diabetic rats through the exosomal transfer of miR-320 into endothelial cells. J Mol Cell Cardiol 2014;74:139-150. 


\section{Kidney \\ Blood Pressure Research}

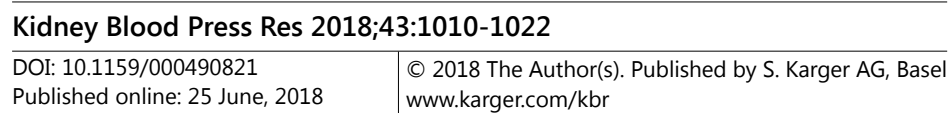

Yu et al.: Exosomes Mediate Peritoneal Membrane Function

20 Sun T, Kalionis B, Lv G, Xia S, Gao W: Role of exosomal noncoding RNAs in lung carcinogenesis. Biomed Res Int 2015;125807.

21 Ismail N, Wang Y, Dakhlallah D, Moldovan L, Agarwal K, Batte K, Shah P, Wisler J, Eubank TD, Tridandapani S: Macrophage microvesicles induce macrophage differentiation and miR-223 transfer. Blood 2013;121:984-995.

22 Chen JH, Borges M: Histopathology and enhanced detection of tumor invasion of peritoneal membranes. PLoS One 2017;12:e0173833.

23 Nakamura K, Sawada K, Kinose Y, Yoshimura A, Toda A, Nakatsuka E, Hashimoto K, Mabuchi S, Morishige $\mathrm{KI}$, Kurachi $\mathrm{H}$ : Exosomes promote ovarian cancer cell invasion through transfer of CD44 to peritoneal mesothelial cells. Mol Cancer Res 2016;15:78-92.

24 Wu J, Xing C, Zhang L, Mao H, Chen X, Liang M, Wang F, Ren H, Cui H, Jiang A: Autophagy promotes fibrosis and apoptosis in the peritoneum during long-term peritoneal dialysis. J Cell Mol Med 2017;22:1190-2201.

25 Zhou Q Bajo MA, Peso GD, Yu X, Selgas R: Preventing peritoneal membrane fibrosis in peritoneal dialysis patients. Kidney Int 2016;90:515-524.

-26 Yanezmo M, Larapezzi E, Selgas R, Ramírezhuesca M, Dominguezjiménez C, Jimenezheffernan JA, Aguilera A, Sancheztomero JA, Bajo MA, Alvarez V: Peritoneal dialysis and epithelial-to-mesenchymal transition of mesothelial cells. N Engl J Med 2003;348:2037-2039.

27 You-Juan FU, Zhang QY: Pathophysiology of the peritoneal membrane failure. Chinese J Nephrol Dialy Transplant 2011;20:76-81.

28 Gerarduzzi C, Di BJ: Myofibroblast repair mechanisms post-inflammatory response: a fibrotic perspective. Inflamm Res 2017;66:451-465.

29 Devuyst 0, Topley N, Williams JD: Morphological and functional changes in the dialysed peritoneal cavity: impact of more biocompatible solutions. Nephrol Dial Transplant 2002;17:12-15.

-30 Kaneko K, Hamada C, Tomino Y: Peritoneal fibrosis intervention. Perit Dial Int 2007;27:S82-86.

-31 Lima SMAD, Otoni A, Sabino ADP, Dusse LMSA, Gomes KB, Pinto SWL, Marinho MAS, Rios DRA: Inflammation, neoangiogenesis and fibrosis in peritoneal dialysis. Clin Chim Acta 2013;421:46-50.

-32 Bertheloot D, Lata E: HMGB1, IL-1 $\alpha$, IL-33 and S100 proteins: dual-function alarmins. Cell Mol Immunol 2017;14:43-64.

-33 Ramalingam TR, Gieseck RL, Acciani TH, Hart KM, Cheever AW, Mentinkkane MM, Vannella KM, Wynn TA: Enhanced protection from fibrosis and inflammation in the combined absence of IL-13 and IFN- $\gamma$. J Pathol 2016;239:344-354.

34 Heerboth S, Housman G, Leary M, Longacre M, Byler S, Lapinska K, Willbanks A, Sarkar S: EMT and tumor metastasis. Clin Transl Med 2015;4:6.

-35 Capobianco A, Cottone L, Monno A, Manfredi AA, Rovere-Querini P: The peritoneum: healing, immunity and diseases. J Pathol 2017;243:137-147.

-36 Graham TR, Zhau HE, Odero-Marah VA, Osunkoya AO, Kimbro KS, Tighiouart M, Liu T, Simons JW, O’Regan RM: Insulin-like growth factor-I-dependent up-regulation of ZEB1 drives epithelial-to-mesenchymal transition in human prostate cancer cells. Cancer Res 2008;68:2479-2488.

-37 Song SJ, Poliseno L, Song MS, Ala U, Webster K, Ng C, Beringer G, Brikbak NJ, Yuan X, Cantley LC: MicroRNAantagonism regulates breast cancer stemness and metastasis via TET-family-dependent chromatin remodeling. Cell 2013;154:311-324.

-38 do Amaral RJ, Benac P, Andrade LR, Farina M, Bernardazzi C, Arcanjo KD, Jr PA, Cordeiro IR, Brito JM, El-Cheikh MC: Peritoneal submesothelial stromal cells support hematopoiesis and differentiate into osteogenic and adipogenic cell lineages. Cells Tissues Organs 2014;200:118-131.

39 Kariya T, Nishimura H, Mizuno M, Suzuki Y, Matsukawa Y, Sakata F, Maruyama S, Takei Y, Ito Y: TGF- $\beta 1$ VEGF-A pathway induces neoangiogenesis with peritoneal fibrosis in patients undergoing peritoneal dialysis. Am J Physiol Renal Physiol 2018;314:F167-180.

40 Fujikake K, Kajiyama H, Yoshihara M, Nishino K, Yoshikawa N, Utsumi F, Suzuki S, Niimi K, Sakata J, Mitsui $\mathrm{H}$ : A novel mechanism of neovascularization in peritoneal dissemination via cancer-associated mesothelial cells affected by TGF- $\beta$ derived from ovarian cancer. Oncol Rep 2017;39:193-200.

41 Wang L, Liu N, Xiong C, Xu L, Shi Y, Qiu A, Zang X, Mao H, Zhuang S: Inhibition of EGF receptor blocks the development and progression of peritoneal fibrosis. J Am Soc Nephrol 2016;27:2631-2644. 


\section{Kidney \\ Blood Pressure Research}

\begin{tabular}{l}
\hline Kidney Blood Press Res 2018;43:1010-1022 \\
\hline \begin{tabular}{l|l} 
DOI: 10.1159/000490821 2018 & $\begin{array}{l}\text { @ 2018 The Author(s). Published by S. Karger AG, Basel } \\
\text { www.karger.com/kbr }\end{array}$ \\
Published online: 25 June, 2018
\end{tabular} \\
\hline
\end{tabular}

Yu et al.: Exosomes Mediate Peritoneal Membrane Function

42 Kanda M, Kodera Y: Molecular mechanisms of peritoneal dissemination in gastric cancer. World J Gastroenterol 2016;22:6829-6840.

43 Buschow SI, Nolte-'t Hoen EN, Van NG, Pols MS, Ten BT, Lauwen M, Ossendorp F, Melief CJ, Raposo G, Wubbolts R: MHC II in dendritic cells is targeted to lysosomes or T cell-induced exosomes via distinct multivesicular body pathways. Traffic 2009;10:1528-1542.

44 Inui M, Martello G, Piccolo S: MicroRNA control of signal transduction. Nat Rev Mol Cell Biol 2010;11:252263.

45 Valadi H, Ekstrom K, Bossios A, Sjostrand M, Lee JJ, Lotvall JO: Exosome-mediated transfer of mRNAs and microRNAs is a novel mechanism of genetic exchange between cells. Nat Cell Biol 2007;9:654-659.

46 Thery C, Zitvogel L, Amigorena S: Exosomes: composition, biogenesis and function. Nat Rev Immunol 2002;2:569-579.

47 Record M, Subra C, Silventepoirot S, Poirot M: Exosomes as intercellular signalosomes and pharmacological effectors. Biochem Pharmacol 2011;81:1171-1182.

48 Lazaroibanez E, Lunavat TR, Su CJ, Escobedolucea C, Cruz ODL, Siljander P, Lotvall J, Yliperttula M: Distinct prostate cancer-related mRNA cargo in extracellular vesicle subsets from prostate cell lines. BMC Cancer 2017;17:92.

49 Thakur BK, Zhang H, Becker A, Matei I, Huang Y, Costasilva B, Zheng Y, Hoshino A, Brazier H, Xiang J: Double-stranded DNA in exosomes: a novel biomarker in cancer detection. Cell Res 2014;24:766-769.

50 Borges FT, Melo SA, BC Ö, Kato N, Revuelta I, Miller CA, Lebleu VS, Kalluri R: TGF-ß1-containing exosomes from injured epithelial cells activate fibroblasts to initiate tissue regenerative responses and fibrosis. J Am Soc Nephrol 2013;24:385-392.

51 Bang C, Batkai S, Dangwal S, Gupta SK, Foinquinos A, Holzmann A, Just A, Remke J, Zimmer K, Zeug A, Ponimaskin E, Schmiedl A, Yin X, Mayr M, Halder R, Fischer A, Engelhardt S, Wei Y, Schober A, Fiedler J, et al.: Cardiac fibroblast-derived microRNA passenger strand-enriched exosomes mediate cardiomyocyte hypertrophy. The Journal of Clinical Investigation 2014;124:2136-2146.

52 Zhu F, Chong Lee Shin OLS, Pei G, Hu Z, Yang J, Zhu H, Wang M, Mou J, Sun J, Wang Y: Adipose-derived mesenchymal stem cells employed exosomes to attenuate AKI-CKD transition through tubular epithelial cell dependent Sox9 activation. Oncotarget 2017;8:70707-70726.

53 Shi J, Yu M, Sheng M: Angiogenesis and inflammation in peritoneal dialysis: The role of adipocytes. Kidney Blood Press Res 2017;42:209-219.

54 Wei M, Yang T, Chen X, Wu Y, Deng X, He W, Yang J, Wang Z: Malignant ascites-derived exosomes promote proliferation and induce carcinoma-associated fibroblasts transition in peritoneal mesothelial cells. Oncotarget 2017;8:42262-42271.

55 Alexandre DLF, Alonsoalconada L, Costa C, Cueva J, Garciacaballero T, Lopezlopez R, Abal M: M-Trap: Exosome-based capture of tumor cells as a new technology in peritoneal metastasis. Eur J Cancer 2015;107:djv184.

56 Sodek KL, Murphy KJ, Brown TJ, Ringuette MJ: Cell-cell and cell-matrix dynamics in intraperitoneal cancer metastasis. Cancer Metastasis Rev 2012;31:397-414.

-57 Frangogiannis NG: Fibroblast-extracellular matrix interactions in tissue fibrosis. Curr Pathobiol Rep 2016;4:1-8.

58 Whiteside TL: The role of tumor-derived exosomes in epithelial mesenchymal transition (EMT). Transl Cancer Res 2017;6:S90-92.

59 Kim J, Kim TY, Lee MS, Mun JY, Ihm C, Kim SA: Exosome cargo reflects TGF- $\beta 1$-mediated epithelial-tomesenchymal transition (EMT) status in A549 human lung adenocarcinoma cells. Biochem Biophys Res Commun 2016;478:643-648.

60 Zhang L, Wu X, Luo C, Chen X, Yang L, Tao J, Shi J: The 786-0 renal cancer cell-derived exosomes promote angiogenesis by downregulating the expression of hepatocyte cell adhesion molecule. Mol Med Rep 2013;8:272-276.

61 Webber J, Steadman R, Mason MD, Tabi Z, Clayton A: Cancer exosomes trigger fibroblast to myofibroblast differentiation. Cancer Res 2010;70:9621-9630.

62 Fang DY, King HW, Li JY, Gleadle JM: Exosomes and the kidney: blaming the messenger. Nephrology(Carlton) 2013;18:1-10. 


\section{Kidney \\ Blood Pressure Research}

63 Wu X, Gao Y, Cui F, Na Z: Exosomes from high glucose-treated glomerular endothelial cells activate mesangial cells to promote renal fibrosis. Biol Open 2016;5:484-491.

64 Huang JH, Yin XM, Xu Y, Xu CC, Lin X, Ye FB, Cao Y, Lin FY: Systemic administration of exosomes released from mesenchymal stromal cells attenuates apoptosis, inflammation, and promotes angiogenesis after spinal cord injury in rats. J Neurotrauma 2017;34:3388-3396.

65 Weis SM, Cheresh DA: Tumor angiogenesis: molecular pathways and therapeutic targets. Nat Med 2011;17:1359-1370.

-66 Ekstrom EJ, Bergenfelz C, Von BV, Serifler F, Carlemalm E, Jonsson G, Andersson T, Leandersson K: WNT5A induces release of exosomes containing pro-angiogenic and immunosuppressive factors from malignant melanoma cells. Mol Cancer 2014;13:88.

-67 Hu GW, Li Q Niu X, Hu B, Liu J, Zhou SM, Guo SC, Lang HL, Zhang CQ, Wang Y: Exosomes secreted by humaninduced pluripotent stem cell-derived mesenchymal stem cells attenuate limb ischemia by promoting angiogenesis in mice. Stem Cell Res Ther 2015;6:10.

68 Gonzalez-King H, GarcaA NA, Ontoria-Oviedo I, Ciria M, Montero JA, Sepaolveda P: Hypoxia inducible factor$1 \alpha$ potentiates Jagged 1-mediated angiogenesis by mesenchymal stem cell-derived exosomes. Stem Cells 2017;35:1747-1759.

-69 Kucharzewska P, Christianson HC, Welch JE, Svensson KJ, Fredlund E, Ringner M, Mprgelin M, Bourseauguilmain E, Bengzon J, Belting M: Exosomes reflect the hypoxic status of glioma cells and mediate hypoxia-dependent activation of vascular cells during tumor development. Proc Natl Acad Sci U S A 2013;110:7312-7317.

-70 Zhang X, Wang X, Zhu H, Kranias EG, Tang Y, Peng T, Chang J, Fan GC: Hsp20 functions as a novel cardiokine in promoting angiogenesis via activation of VEGFR2. PLoS One 2012;7:e32765.

71 Ke X, Yang D, Liang J, Wang X, Wu S, Wang X, Hu C: Human endothelial progenitor cell-derived exosomes increase proliferation and angiogenesis in cardiac fibroblasts by promoting the mesenchymal-endothelial transition and reducing high mobility group Box 1 Protein B1 expression. DNA Cell Biol 2017;36:10181028.

-72 Martello G, Rosato A, Ferrari F, Manfrin A, Cordenonsi M, Dupont S, Enzo E, Guzzardo V, Rondina M, Spruce T: A MicroRNA targeting dicer for metastasis control. Cell 2010;141:1195-1270.

-73 Strippoli R M-VR, Battistelli C, Cicchini C, Noce, Amicone L, Marchetti A, Del Pozo MA, Tripodi M: Molecular mechanisms underlying peritoneal EMT and fibrosis. Stem Cells Int 2016:3543678.

74 Miranda KC, Bond DT, Mckee M, Skog J, Paunescu TG, Da SN, Brown D, Russo LM: Nucleic acids within urinary exosomes/microvesicles are potential biomarkers for renal disease. Kidney Int 2010;78:191-199.

75 Lv LL, Cao YH, Ni HF, Xu M, Liu D, Liu H, Chen PS, Liu BC: MicroRNA-29c in urinary exosome/microvesicle as a biomarker of renal fibrosis. Am J Physiol Renal Physiol 2013;305:F1220-1227.

76 Afonso MB, Rodrigues PM, Simao AL, Rui EC: Circulating microRNAs as potential biomarkers in nonalcoholic fatty liver disease and hepatocellular carcinoma. J Clin Med 2016;5:30.

-77 Gibbings DJ, Ciaudo C, Erhardt M, Voinnet O: Multivesicular bodies associate with components of miRNA effector complexes and modulate miRNA activity. Nat Cell Biol 2009;11:1143-1149.

-78 Qu Y, Zhang Q Cai X, Li F, Ma Z, Xu M, Lu L: Exosomes derived from miR-181-5p-modified adipose-derived mesenchymal stem cells prevent liver fibrosis via autophagy activation. J Cell Mol Med 2017;21:2491-2502.

-79 Han R, Ji X, Rong R, Li Y, Yao W, Yuan J, Wu Q, Yang J, Yan W, Han L: MiR-449a regulates autophagy to inhibit silica-induced pulmonary fibrosis through targeting Bcl2. J Mol Med(Berl) 2016;94:1267-1279.

$\$ 80$ Newman MA, Thomson JM, Hammond SM: Lin-28 interaction with the Let-7 precursor loop mediates regulated microRNA processing. RNA 2008;14:1539-1549.

81 Park JT, Kato M, Lanting L, Castro N, Nam BY, Wang M, Kang SW, Natarajan R: Repression of let-7 by transforming growth factor- $\beta 1$-induced Lin28 upregulates collagen expression in glomerular mesangial cells under diabetic conditions. Am J Physiol Renal Physiol 2014;307:F1390-1403.

-82 Ohshima K, Inoue K, Fujiwara A, Hatakeyama K, Kanto K, Watanabe Y, Muramatsu K, Fukuda Y, Ogura $\mathrm{S}$, Yamaguchi K: Let-7 microRNA family is selectively secreted into the extracellular environment via exosomes in a metastatic gastric cancer cell line. PLoS One 2010;5:e13247.

-83 Matsuura K, Giorgi VD, Schechterly C, Wang RY, Farci P, Tanaka Y, Alter HJ: Circulating let-7 levels in plasma and extracellular vesicles correlate with hepatic fibrosis progression in chronic hepatitis C. Hepatology 2016;64:732-745. 


\section{Kidney \\ Blood Pressure Research}

84 Donnarumma E, Fiore D, Nappa M, Roscigno G, Adamo A, Iaboni M, Russo V, Affinito A, Puoti I, Quintavalle C: Cancer-associated fibroblasts release exosomal microRNAs that dictate an aggressive phenotype in breast cancer. Oncotarget 2017;8:19592-19608.

85 Ichii O, Ohta H, Horino T, Nakamura T, Hosotani M, Mizoguchi T, Morishita K, Nakamura K, Hoshino Y, Takagi S: Urinary exosome-derived microRNAs reflecting the changes of renal function and histopathology in dogs. Sci Rep 2017;7:40340.

-86 Kobayashi M, Salomon C, Tapia J, Illanes SE, Mitchell MD, Rice GE: Ovarian cancer cell invasiveness is associated with discordant exosomal sequestration of Let-7 miRNA and miR-200. J Transl Med 2014;12:4.

-87 Roderburg C, Urban GW, Bettermann K, Vucur M, Zimmermann H, Schmidt S, Janssen J, Koppe C, Knolle P, Castoldi M: Micro-RNA profiling reveals a role for miR-29 in human and murine liver fibrosis. Hepatology 2011;53:209-218.

88 Solemarce C, Corteshernandez J, Vidal M, Felip ML, Ordiros J: MiR-29C in urinary exosomes as predictor of early renal fibrosis in lupus nephritis. Nephrol Dial Transplan 2015;30:1488-1496.

89 Chen Li, Brigstock David: Exosomal microRNA modulates pathways of liver fibrosis by regulating connective tissue growth factor (CTGF) expression in fibrogenic cells during chronic injury. FASEB Journal 2013;27:lb440.

90 Lopez-Anton M, Lambie M, Lopez-Cabrera M, Schmitt CP, Ruiz-Carpio V, Bartosova M, Schaefer B, Davies S, Stone T, Jenkins R: MiR-21 promotes fibrogenesis in peritoneal dialysis. Am J Pathol 2017;187:1537-1550.

-91 Xiao J, Pan Y, Li XH, Yang XY, Feng YL, Tan HH, Jiang L, Feng J, Yu XY: Cardiac progenitor cell-derived exosomes prevent cardiomyocytes apoptosis through exosomal miR-21 by targeting PDCD4. Cell Death Dis 2016;7:e2277.

-92 Csak T, Bala S, Lippai D, Satishchandran A, Catalano D, Kodys K, Szabo G: MicroRNA-122 regulates hypoxiainducible factor-1 and vimentin in hepatocytes and correlates with fibrosis in diet-induced steatohepatitis. Liver Int 2015;35:532-541.

\$3 Hyun J, Wang S, Kim J, Kim GJ, Jung Y: MicroRNA125b-mediated Hedgehog signaling influences liver regeneration by chorionic plate-derived mesenchymal stem cells. Sci Rep 2015;5:14135.

$\$ 94$ Bigagli E, Luceri C, Guasti D, Cinci L: Exosomes secreted from human colon cancer cells influence the adhesion of neighboring metastatic cells: Role of microRNA-210. Cancer Biol Ther 2016;17:1062-1069.

$\$ 95$ Taddei ML, Cavallini L, Comito G, Giannoni E, Folini M, Marini A, Gandellini P, Morandi A, Pintus G, Raspollini MR: Senescent stroma promotes prostate cancer progression: the role of miR-210. Mol Oncol 2014;8:1729-1746.

-96 Ottaviani L, De Windt LJ, da Costa Martins PA: Exosomes: scytales in the damaged heart. Ann Transl Med 2016;4:222.

-97 Semenza GL: Hypoxia-inducible factor 1: master regulator of 02 homeostasis. Curr Opin Genet Dev 1998;8:588-594.

-98 Guimbellot JS, Erickson SW, Mehta T, Wen H, Page GP, Sorscher EJ, Hong JS: Correlation of microRNA levels during hypoxia with predicted target mRNAs through genome-wide microarray analysis. BMC Med Genomics 2009;2:15.

-99 Kang T, Jones TM, Clayton N, Methode B, Calvert JW, Thompson WE, Bond VC, Chen YE, Dong L: Adiposederived stem cells induce angiogenesis via microvesicle transport of miRNA-31. Stem Cells Transl Med 2016;5:440-450.

100 Wu C, Chen J, Chen C, Wang W, Wen L, Gao K, Chen X, Xiong S, Zhao H, Li S: Wnt/ $\beta$-catenin coupled with HIF-1 $\alpha$ /VEGF signaling pathways involved in galangin neurovascular unit protection from focal cerebral ischemia. Sci Rep 2015;5:16151.

101 Fan GC: Hypoxic exosomes promote angiogenesis. Blood 2014;124:3669-3670.

102 Umezu T, Tadokoro H, Azuma K, Yoshizawa S, Ohyashiki K, Ohyashiki JH: Exosomal miR-135b shed from hypoxic multiple myeloma cells enhances angiogenesis by targeting factor-inhibiting HIF-1. Blood 2014;124:3748-3757.

103 Tornavaca O, Chia M, Dufton N, Almagro LO, Conway DE, Randi AM, Schwartz MA, Matter K, Balda MS: ZO-1 controls endothelial adherens junctions, cell-cell tension, angiogenesis, and barrier formation. J Cell Biol 2015;208:821-838. 


\section{Kidney \\ Blood Pressure Research}

Kidney Blood Press Res 2018;43:1010-1022

DOI: 10.1159/000490821

Published online: 25 June, 2018

(C) 2018 The Author(s). Published by S. Karger AG, Base

www.karger.com/kbr

1022

Yu et al.: Exosomes Mediate Peritoneal Membrane Function

104 Rodriguez PL, Jiang S, Fu Y, Avraham S, Avraham HK: The proinflammatory peptide substance P promotes blood-brain barrier breaching by breast cancer cells through changes in microvascular endothelial cell tight junctions. Int J Cancer 2014;134:1034-1044.

105 Hsu YL, Hung JY, Chang WA, Lin YS, Pan YC, Tsai PH, Wu CY, Kuo PL: Hypoxic lung cancer-secreted exosomal miR-23a increased angiogenesis and vascular permeability by targeting prolyl hydroxylase and tight junction protein ZO-1. Oncogene 2017;36:4929-4942.

106 Lee JK, Park SR, Jung BK, Jeon YK, Lee YS, Kim MK, Kim YG, Jang JY, Kim CW: Exosomes derived from mesenchymal stem cells suppress angiogenesis by down-regulating VEGF expression in breast cancer cells. PLoS One 2013;8:e84256.

107 Pakravan K, Babashah S, Sadeghizadeh M, Mowla SJ, Mossahebi-Mohammadi M, Ataei F, Dana N, Javan M: MicroRNA-100 shuttled by mesenchymal stem cell-derived exosomes suppresses in vitro angiogenesis through modulating the mTOR/HIF-1 $\alpha$ /VEGF signaling axis in breast cancer cells. Cellular Cell Oncol 2017;40:457-470.

108 Luo Q Guo D, Liu G, Chen G, Hang M, Jin M: Exosomes from miR-126-overexpressing adscs are therapeutic in relieving acute myocardial ischaemic injury. Cell Physiol Biochem 2017;44:2105-2116.

109 Jiang W, Zhang W, Wu L, Liu L, Men Y, Wang J, Liang J, Hui Z, Zhou Z, Bi N, Wang L. MicroRNA-related polymorphisms in PI3K/Akt/mTOR pathway genes are predictive of limited-disease small cell lung cancer treatment outcomes. Biomed Res Int 2017;2017:6501385.

110 Lin S, Zhang Q Shao X, Zhang T, Xue C, Shi S, Zhao D, Lin Y: IGF-1 promotes angiogenesis in endothelial cells/adipose-derived stem cells co-culture system with activation of PI3K/Akt signal pathway. Cell Prolif 2017;50:e12390.

-111 Beltrami C, Besnier M, Shantikumar S, Shearn AI, Rajakaruna C, Laftah A, Sessa F, Spinetti G, Petretto E, Angelini GD: Human pericardial fluid contains exosomes enriched with cardiovascular-expressed microRNAs and promotes therapeutic angiogenesis. Mol Ther 2017;25:679-693.

112 van Balkom BW, de Jong OG, Smits M, Brummelman J, Den OK, de Bree PM, van Eijndhoven MA, Pegtel DM, Stoorvogel W, Wurdinger T: Endothelial cells require miR-214 to secrete exosomes that suppress senescence and induce angiogenesis in human and mouse endothelial cells. Blood 2013;121:3997-4006, S1-15. 